\title{
Prescribing for patients attending old age psychiatry day hospitals
}

\author{
Margaret M. Semple, Brian R. Ballinger and Elizabeth Irvine
}

\begin{abstract}
A reviow of the drug treatment of 163 patients aftending two old aos poychiatilic doy hosplials showed that 29 recelved medication from the doy hoeplial, 44 from general proctifioners and 60 from both sources. Many of the potients' knowledge of thelr chug treatiment was incomplete. Of those individucts interviewed, cpproxlmately equal numbers expresesed a preference for day hospltal and eneral practitioner prescriptions. The origin of the prescription ald not becr any obvious relationship to subesequent admistion to hosplital or continued attendance of the doy hospltal.
\end{abstract}

Patients attending old age psychiatry day hospitals may receive prescribed drugs from both the hospital and their general practitioners (GPs). The practice followed varies from centre to centre, and may not always be based on a systematic analysis of patients' needs and wishes. Non-compliance can be a problem (Ballard et al, 1991).

The aim of this study was to analyse the prescribing of drugs in two day hospitals and compare them with reports of GP prescribing. Patients' preferences were sought and the outcome of care is also reviewed.

\section{The study}

The study was carried out in two old age psychiatric day hospitals, Menzieshill (DH1) and Ashludie (DH2), serving the city of Dundee. The day hospitals had a total of 50 places per day and a total of 163 patients attending ( 120 female, 43 male). DH1 treated women from the west side of the city while DH2 treated women from the east side of the city and the men from the entire city. The study was completed in a seven month period from July 1991 to January 1992. Information about GP prescribing was collected routinely at the start of day hospital attendance using a standard form and this was repeated during the study period.

Information about day hospital prescribing was collected on a standard form, noting drug doses, times of administration and date of initial prescription. Drugs supplied to take away were recorded. When a drug was prescribed by the day hospital the staff were asked for the reason.

Information was collected from the patients' case records and included age, duration and frequency of attendance and diagnosis. The Information/Orientation section of the Clifton Assessment Procedures for the Elderly scale (McPherson et al, 1985) was completed by one of the authors. Patients were interviewed about their views using a structured questionnaire.

The outcome of treatment was defined in terms of continued attendance at six months after the initial part of the study.

\section{Findings}

\section{Patients studied}

The age range of the 163 patients was from 57 to 93 years, with a mean of 76.6 years (s.d. $=8.17$ ). There were $14(9 \%)$ people under 65 and these included seven men. The primary diagnosis in $107(66 \%)$ of these patients was dementla and the others suffered from affective psychosis, other depressive disorders, neurotic disorders, paranoid states, alcohol dependence, schizophrenia. alcoholic psychosis, organic psychosis, other psychoses and mild mental retardation.

In the whole group, $133(82 \%)$ were on medication at the time the survey was done. Of these 133 individuals $40(30 \%)$ were on nonpsychotropic medication only, 16 (12\%) were on psychotropic medication only and 77 (58\%) were on a combination of psychotropic and nonpsychotropic medication. Twenty-nine (22\%) patients were on medication prescribed by the day hospitals, 44 (33\%) were on medication from the GPs and $60(45 \%)$ recetved medication from both sources.

\section{Length of attendance}

The mean duration of attendance was 13.1 months and $110(67 \%)$ of patients had been attending for less than one year. Twenty-eight (17\%) had attended between one and two years, 
17 (10\%) between two and five years and 8 (5\%) for more than five years.

\section{Diagnosis and prescription}

In those patients with a primary diagnosis of organic brain disease (ICD-9 291,293,294,303, 310,317; WHO, 1978), 96 out of 120 (80\%) were on medication. Thirty-seven out of 43 (86\%) individuals with a functional illness diagnosis (ICD-9 295,296,297,300,311) were on prescrtbed medication (Table 1).

\section{Patients' knowledge of drug treatment}

Naming drugs. Eighty-three (51\%) of the 163 patients were available, willing and fit to be interviewed about the naming of their drugs. As one would expect, 21 out of 26 (81\%) of the more cognitively impaired patients (Clifton score $\leqslant 6$ ) knew none of their drugs' names. Thirty-four out of $57(60 \%)$ of the less cognittvely impaired patients (Clifton scores $\geqslant 7$ ) knew none of their drugs' names. Within the group assessed, 53 out of 83 (69\%) knew none of their drugs, 17 (21\%) knew one or more and 11 (13\%) knew them all.

Understanding the nature of drugs. Eighty-four (51\%) of the 163 patients were interviewed about their understanding of their medication, the remainder being unavailable or unable to be interviewed. Within this group 54 (64\%) knew the purpose of one or more of their drugs, 26 (31\%) knew nothing about their drugs' purpose and four (5\%) gave an inappropriate response. Thirteen out of 26 (50\%) of the more cognittvely impaired patients (Clifton score $\leqslant 6$ ) understood the nature of one or more of their prescribed drugs. Forty-four out of 58 (76\%) of the less cognitively impaired patients (Clifton score $\geqslant 7$ ) knew the nature of one or more of their drugs.

\section{Prescription preferences}

One hundred and twenty patients were interviewed about their prescription preferences, the remainder were unavailable or unwilling to be interviewed and not all those seen were actually receiving drugs. Forty-six individuals (38\%) preferred to have their drugs prescribed by the day hospital, 44 (37\%) preferred to have their drugs prescribed by their GP and the rematning 30 (25\%) did not have a preference.

Forty-one out of 51 (82\%) of the more cognithely impaired group (Chiton score $\leqslant 6$ ) preferred to have their GP prescribing or did not have a preference. Thirty-three out of $69(48 \%)$ of the less cognittively impaired group (Clifton score $\geqslant 7$ ) preferred to have thetr GP prescribing or did not have a preference $\left(x^{2}=13.09\right.$, d.f. $\left.=1, P<0.01\right)$.

A variety of reasons were offered for prescription preferences. In 65 patients it was due to personal convenience and 20 felt that their preferred prescriber knew them best. Other reasons given were generally inappropriate.

Among those 44 patients expressing a preference for the GP as prescriber only 22 (50\%) were actually being prescribed drugs by the GP alone, three (7\%) were on no medication, 18 (41\%) were being prescribed medication by both GP and day hospital, and one (2\%) was being prescribed drugs from the day hospital. Of the 46 who preferred day hospltal prescribing only 11 (24\%) recetved medicines from the day hospital alone, four (9\%) were on no medication, 18 (39\%) were being prescribed medication from both GP and day hospital, and 13 (28\%) were being given prescriptions by the GP.

\section{Discharge and continued attendance}

At stx months' follow-up, 85 (52\%) of the 163 patients were still attending the day hospital. Forty-eight (29\%) were discharged to residential homes for the elderly, nursing homes and their own homes. Twenty-six (16\%) were discharged into psychiatric in-patient care and four (3\%) had died.

The prescribers of psychotropic drugs (1.e. day hospital versus GP) were compared to ascertain whether the source of prescription was related to the whereabouts of the patients at stx months follow-up (Table 2). There were no significant differences in outcome for patients in the different groups.

\section{Comment}

Some caution must be exercised in interpreting these results as not all patients were interviewed. Information about drug changes in general practice was not always complete. Patients'

Table 1. Medication per diagnostic group

\begin{tabular}{|c|c|c|c|c|c|c|}
\hline Dicenoak & Number of patients & Pyychotropic medicetion & Non-poychotropic mectication & Doth & Noliner & MA \\
\hline $\begin{array}{l}\text { Organic } \\
\text { Functional }\end{array}$ & $\begin{array}{r}120 \\
43\end{array}$ & $\begin{array}{r}11 \\
5\end{array}$ & $\begin{array}{r}31 \\
9\end{array}$ & $\begin{array}{l}54 \\
23\end{array}$ & $\begin{array}{c}18 \\
1\end{array}$ & $\begin{array}{l}6 \\
5\end{array}$ \\
\hline
\end{tabular}


Table 2. Six months follow-up and prescribing agency

\begin{tabular}{lllllcr}
\hline Prescriber & Aftending day hospltal & Poychiatic in-patient & RHE & Nursing home & Home & Died \\
\hline GP & 25 & 4 & 1 & 5 & 9 & \\
Day hospltal & 17 & 7 & 1 & 1 & 2 & 1 \\
Both & 29 & 13 & 1 & 3 & 11 & 3 \\
Nelther & 2 & 1 & 2 & 2 & 2 & \\
Not known & 12 & 1 & 2 & 2 & 4 & \\
\hline
\end{tabular}

RHE, residential homes for the elderly.

preference for GP or hospital prescribing varied, and suggests that the current practice of prescribing for some but leaving provision of other drugs to GPs may be appropriate. However, patients' preferences were not always being followed, although it should be recognised that many suffered from dementia or other illnesses and this would make it difficult for them to understand the situation. No preferences were available from carers and these would also be relevant and may often not coincide with those of the patients.

There was no evidence for any difference in outcomes in terms of hospital and residential care although the measures were relattvely crude and incomplete. Information about compliance was not available. If there is no clear difference in outcome it is suggested that patients' and carers' convenience should be an important factor. although the details of the patient's illness and social situation will also be relevant. A mixture of hospital and GPs' prescription of drugs may present potential difficulties because of drug interactions so full communication is essential (Pharmaceutical Services for Older People, 1989). The pattern of prescription for individual patients must be judged from both clinical need and patient preference.

\section{Acknowledgement}

We wish to thank the medical and nursing staff at the Day Hospital for their assistance and permission to interview the patients.

\section{References}

BAUARD, C. G., MOHAN, R. N. C., HANDY, O. S., et al (1991) Medication complance and dispensing among psychogerlatric patients. Psychiatic Bullettn, 18, 624-625. McPherson, F. M., GAMSU, C. V., Knemie, G., et al (1985) The concurrent validity of the survey version of the Clifton Assessment Procedures for the Elderty (CAPE). Brttish Journal of Clinical Psychology, 24, 83-91.

Pharmaceutical Services for OIDER Propie (1989) Practical Guddance: Report by a Working Group of the National Pharmaceutical Consultatue Committee. Edinburgh: HMSO. WORID HEAlth Organizamon (1978) Mental Dlsorders: Glossary and Guide to thetr Classification in Accordance with the Ninth Revision of the International Classification of Diseases (ICD-9). Geneva: WHO.

*Margaret M. Semple, Consultant Psychiatrist, Hairmyres Hospital, East Kilbride, Lanarkshire G75 8RG; Brian R. Ballinger, Consultant Psychiatrist, Royal Dundee Liff Hospital, Birkhill by Dundee DD2 5NF, and Elizabeth Irvine, Clinical Audit Assistant, Royal Dundee Liff Hospital, Birkhill by Dundee DD2 5NF

*Correspondence 